\title{
Springer Spaniel
}

National Cancer Institute

\section{Source}

National Cancer Institute. Springer Spaniel. NCI Thesaurus. Code C53886.

The Springer Spaniel is a compact, medium-sized dog with long pendant ears. The feet are compact. Its medium-leng th coat is flat or wavy and feathered and comes in liver and white, and black and white, blue or liver roan. Height: 18-21 inches $(46-56 \mathrm{~cm}$.) Weight: $40-55$ pounds $(18-25 \mathrm{~kg}$.) 